\title{
The cell-type-specific activator region of c-Jun juxtaposes constitutive and negatively regulated domains
}

\author{
Vijay R. Baichwal, ${ }^{1}$ Adam Park, ${ }^{1}$ and Robert Tjian \\ Howard Hughes Medical Institute and Department of Molecular and Cell Biology, University of California, Berkeley, \\ California 94720 USA
}

\begin{abstract}
Dissection of the cell-type-specific activation region in c-Jun reveals two functionally separable regulatory subdomains. One subdomain (a1) functions as a transcriptional activator; adjacent to it is a newly identified domain $(\epsilon)$ which, together with the previously defined $\delta$ region, interacts with a cellular factor that modulates the action of a1. Mutants that lack $\epsilon$ are constitutively active and do not interact with the cell-type-specific repressor, whereas mutants that have sustained changes in al exhibit a reduced trans-activation potential but retain the ability to interact with the repressor. This bipartite and modular organization of the a1/€ domain is further established by demonstrating that a1 can be replaced by the heterologous acidic activator of VP16 and retain proper negative regulation by the cell-specific c-Jun inhibitor along with $\epsilon$ and $\delta$. Repression of Jun activity by the inhibitor is not caused by a change in stability, nuclear localization, or DNA-binding activity of the protein. Instead the inhibitor apparently regulates transcriptional activation by interacting directly with $\delta / \epsilon$ and perhaps masking the a1 domain. These studies suggest that multifunctional activation domains, which are structurally complex, may play an important role in the mechanisms that govern inducible tissue-specific gene expression.
\end{abstract}

[Key Words: Cell-type-specific activation region; c-Jun; transcriptional activator; regulated activation domain; AP-1]

Received May 4, 1992; revised version accepted June 12, 1992.

The AP-1 family of regulatory proteins play a pivotal role in cellular proliferation. Prototypic members of this family c-Fos and c-Jun are proto-oncogene products, and an increase in AP-1 activity is the earliest nuclear response of cells stimulated by growth-promoting agents and mitogens (for review, see Curran and Franza 1988; Angel and Karin 1991). This enhancement of AP-1 activity is brought about by both post-translational changes in the Jun and Fos proteins and an increase in intracellular amounts of these proteins. Much attention has been focused on unraveling the mechanisms by which the activity of these proteins is regulated by extracellular signals.

The Jun and Fos proteins belong to the class of basic leucine zipper (bZip) transcription factors. The DNAbinding domain of c-Jun is located in the carboxyl terminal half of the protein and consisits of a region rich in basic amino acid residues, which probably contacts DNA, and a heptad repeat of leucine residues, which provides a surface for dimerization of the protein (for review, see Vogt and Morgan 1990). The transcriptional activation domains $\mathrm{A} 1, \mathrm{~A} 2$, and a negative regulatory region, $\delta$, are located in the amino-terminal half of the protein (Bohmann and Tjian 1989; Baichwal and Tjian

${ }^{1}$ Present address: Tularik Inc., Belmont, California 94002 USA.
1990). Thus, the Jun protein offers several potential targets for regulation.

One level at which Jun function is regulated is sequence-specific DNA-binding activity. A phosphorylation-dephosphorylation reaction and a redox reaction have been described that regulate DNA-binding activity of c-Jun in vitro (Abate et al. 1990; Boyle et al. 1991). Exposure of cells to the tumor promoter TPA causes dephosphorylation of a site near the DNA-binding domain and an increase in c-Jun DNA-binding activity. The potential to alter Jun DNA-binding activity by heteromeric interactions with other proteins through the dimerization domain also exists, and a cellular factor that negatively regulates AP-1 activity has been described (Auwerx and Sassone-Corsi 1991). Also, the cAMP response element binding/activating transcription factor (CREB/ ATF) family proteins heteromerize with c-Jun and alter its DNA-binding specificity (for review, see Lamb and McKnight 1991). Several studies have demonstrated that c-Jun protein is multiply phosphorylated in cells and in vitro with different kinases (Alvarez et al. 1991; Black et al. 1991; Pulverer et al. 1991; Smeal et al. 1991). The consequences of these phosphorylation events, however, are known in only a few cases. Mutagenesis studies show that the sites of phosphorylation by the MAP kinases are important for c-Jun function in cells. 
The transcriptional activity of c-Jun is also subject to regulation, independent of changes in its DNA-binding activity (for review, see Lewin 1991). Previously, we have found that the transcriptional activity of Jun is regulated by a cell-specific factor (Baichwal and Tiian 1990). Control of c-Jun activity by this putative regulator was revealed in a transfection assay. In some cell lines, transactivation by chimeric Jun proteins having the $\delta, A l$, and A2 domains of Jun and a DNA-binding and dimerization domain from a different transcription factor was enhanced by transfection of c-Jun, suggesting that a factor in these cells was regulating transcriptional activation by the Jun domains in the chimera. This observation also indicated that it was possible to deregulate the Jun domains by providing excess c-Jun, which probably competed for binding to the factor and titrated it from the chimera. Analysis of mutant proteins with this in vivo competition assay revealed that the region targeted by the regulatory factor overlapped with the Al transcriptional activation domain and that the $\delta$ domain is essential for efficient interaction between the regulator and Jun. v-Jun, the oncogene of the avian sarcoma virus, ASV-17, lacks the $\delta$ region, and a chimera having the amino-terminal half of $\mathrm{v}$-Jun is not repressed to the same extent as a c-Jun chimera. This observation coupled with the finding that removal of the $\delta$ region from c-Jun enhances its transforming activity in chicken embryo fibroblasts (CEFs) underscored the importance of the putative c-Jun regulator in modulating the function of c-Jun (Bos et al. 1990). The importance of this regulator in controlling Jun activity was further emphasized by the finding that the increase in AP-1 activity seen on expression of the src or ras oncogenes is brought about, at least in part, by down-regulation of the Jun : regulator interaction and activation of the Al domain (Baichwal et al. 1991 ).

The studies on regulation of the Al domain did not establish the manner in which Al activity is controlled. Two scenarios could explain the previous observations. In one, the Al region could harbor an inducible activation domain in a situation reminiscent of the regulation of the activation domain from the CREB transcription factor by protein kinase A /Gonzalez and Montminy 1989; Lee et al. 1990). Sequences within Al would have to be modified, perhaps by phosphorylation, to function as an activation domain, and the negative regulator of $\mathrm{A} 1$ would function by preventing this modification or facilitating its reversal. In the competition assay, titration of the negative regulator, which may be limiting, would result in activation of A1. Such a possibility has been raised on the basis of finding sites within and near the $\delta$ region that are phosphorylated by the regulatory MAP kinases (Pulverer et al. 1991; Smeal et al. 1991). An alternate scenario for the regulation of the Al region, which we have favored, would be that the sequences within this region encode a fully functional constitutive transcriptional activation domain and that the negative regulator would bind at or near the activation domain to repress it. In this mode of regulation, the negative regulator would function as an inhibitor, and its titration in the competition assay would lead to relief of repression of the Al domain.

Here, we have used the in vivo competition assay to dissect the $\mathrm{Al}$ region and distinguish between the two possible modes of regulation. Deletion and point mutations have been made within this region, and the mutants have been assayed for their effect on the transactivation potential of chimeric Jun proteins and also for their effect on the interaction of the negative regulator with Jun. Our results show that the Al region consists of a bipartite activation domain that is composed of an interaction site for an inhibitor and a separable activation domain. The bipartite nature has been established by demonstrating that a constitutive activation domain from a different protein is regulated by the inhibitor, when it is substituted for the Jun activation domain. These findings reveal a new mode of regulation for an activation domain of a transcription factor and help to explain why $\mathrm{v}$-Jun, although more active than c-Jun, is still regulated by the inhibitor.

\section{Results}

The $A 1$ region of $c$-Iun contains a negative regulatory site

An in vivo competition assay has been used previously to demonstrate that c-jun transcriptional activity is regulated in some cells (Baichwal and Tjian 1990). In this assay, a gal4 : jun or jun : E2 hybrid is transfected with the corresponding reporter plasmid and a vector expressing c-Jun or a vector lacking Jun sequences. The hybrid protein has the regulatory sequences of Jun (amino acids 5-253, which includes the $\delta, A 1$, and A2 domains) fused to the DNA-binding and dimerization domains from the yeast transcriptional activator GAL4 or from the transcriptional activator of bovine papilloma virus (BPV), E2. Inclusion of $\mathrm{c}$-Jun in the transfection results in an increased trans-activation by the hybrid. This superenhancement of trans-activation has been interpreted to result from titration by c-Jun of a cellular factor that regulates transcriptional activity of the hybrid. Analysis of this superenhancement phenomenon by examining various c-Jun mutants as competitors and gal4 : jun hybrids having different parts of Jun revealed that the Al domain was the target of regulation. The amino-terminal boundary was amino acid 92, as removal of more amino acids from this end resulted in a hybrid that was no longer superenhanced. The carboxy-terminal boundary of A1 was mapped maximally to amino acid 154, as GAL4 : Jun hybrids lacking the A2 domain and having amino acids 5-154 of Jun were superenhanced. The A1 region also encompassed an activation domain, as deletions from the amino terminus that went beyond amino acid 92 resulted in proteins that had considerably lower trans-activation potential in cell lines that lacked the negative regulator of jun.

To analyze the regulation of the $\mathrm{Al}$ region by this cellular factor, gal4 : jun hybrids that had deletions to varying extents from the carboxy-terminal boundary of A1 
were examined in the competition assay. In $\mathrm{L}-\mathrm{M}\left(\mathrm{TK}^{-}\right)$ cells, which have the c-Jun inhibitory activity, a GAL4 : Jun hybrid that has amino acids 5-137 from Jun was superenhanced to a similar extent as GAL4 : Jun 5-253 or GAL4 : Jun 5-154 (Fig. 1). Interestingly a hybrid that lacks 27 more amino acids from the carboxyl terminus (GAL4 : Jun 5-110) was more active than the longer hybrids in the absence of the competitor and more importantly was not superenhanced by c-Jun. Removal of more amino acids from the carboxyl terminus (GAL4: Jun 5-77) generated a hybrid that no longer trans-activated and was also not superenhanced. Transfection of the same gal4: jun derivatives into HepG2 cells, which lack the Jun regulatory activity (Fig. 1, HepG2), demonstrated that gal4 : jun 5-110 differed significantly from the hybrids having more jun sequences only in $\mathrm{L}-\mathrm{M}\left(\mathrm{TK}^{-}\right)$cells. Taken together, these results suggest that amino acids $110-137$ (termed the $\epsilon$ region) represent a site in the $\mathrm{Al}$ region that is essential for action of the regulatory factor and that sequences between amino acids 92 and 110 (termed the al region) function as an activation domain.

To determine whether the Al region is composed of two domains, al and $\epsilon$, mutations were made that would specifically affect the integrity of one region without affecting the other. These mutations were reconstructed in a jun : E2 hybrid to assess their effect on trans-activation and their capacity to be superenhanced by jun. As seen previously, v-jun: E2, which lacks the negative regulatory $\delta$ region, but has an intact $\epsilon$ region, was superenhanced by c-jun, indicating that it was still subject to regulation as with c-jun : E2 (Fig. 2). In contrast, the jun : E2 hybrid lacking $\epsilon$ was constitutively active in $\mathrm{L}-\mathrm{M}\left(\mathrm{TK}^{-}\right)$cells. It was a better trans-activator than c-Jun : E2 and was not superenhanced by c-Jun, implying that it was no longer repressed by the inhibitor. The Jun : E2 hybrids with deletions of the al region (amino acids 92-103 or 92-107) and a hybrid having changes in al (the sequence TTTPTPT changed to AAAPAPA) trans-activated poorly or not at all in the presence or absence of the competitor, suggesting that these changes impaired the trans-activation function of A1. In HepG2 cells the jun : E2 hybrid lacking $\epsilon$ was as active as c-jun : E2, confirming that removal of the $\epsilon$ region-enhanced trans-activation only in a cell line having the inhibitor. As expected, hybrids with changes in al had

A

\begin{tabular}{|c|c|c|c|c|c|}
\hline \multirow{3}{*}{ ACTIVATOR } & & \multicolumn{3}{|c|}{$\mathrm{L}-\mathrm{M}\left(\mathrm{TK}^{-}\right)$} & \multirow{3}{*}{$\begin{array}{c}\text { HepG2 } \\
\text { Relative } \\
\text { CAT activity }\end{array}$} \\
\hline & \multirow[t]{2}{*}{$\begin{array}{l}\text { SCHEMATIC } \\
\text { STRUCTURE }\end{array}$} & $\begin{array}{r}\text { Rel } \\
\text { CAT a }\end{array}$ & $\begin{array}{l}\text { ive } \\
\text { ivity }\end{array}$ & \multirow{2}{*}{$\begin{array}{c}\text { Fold } \\
\text { increase }\end{array}$} & \\
\hline & & -Comp. & Comp. & & \\
\hline GAL4:jun 5-253 & : & 13 & 110 & 8.5 & 20 \\
\hline GAL4:jun 139-253 & i & 10 & 14 & 1.5 & 3.5 \\
\hline GAL4:jun 5-154 & 㱠 & 12 & 160 & 13 & 55 \\
\hline GAL4:jun $5-150$ & (a) & 5 & 100 & 20 & 20 \\
\hline GAL4:jun 5-137 & (i) & 6 & 84 & 14 & 12 \\
\hline GAL4:jun 5-110 & mi! & 70 & 60 & 0.9 & 55 \\
\hline GAL4:jun 5-110* & (a) & 190 & 100 & 0.5 & 50 \\
\hline GAL4:jun 5-77 & 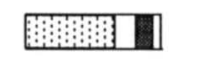 & $<3$ & $<3$ & $--\cdot$ & $<2$ \\
\hline
\end{tabular}

B

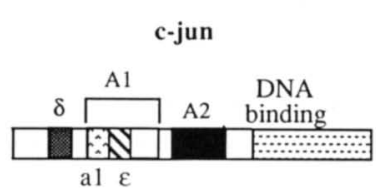


A

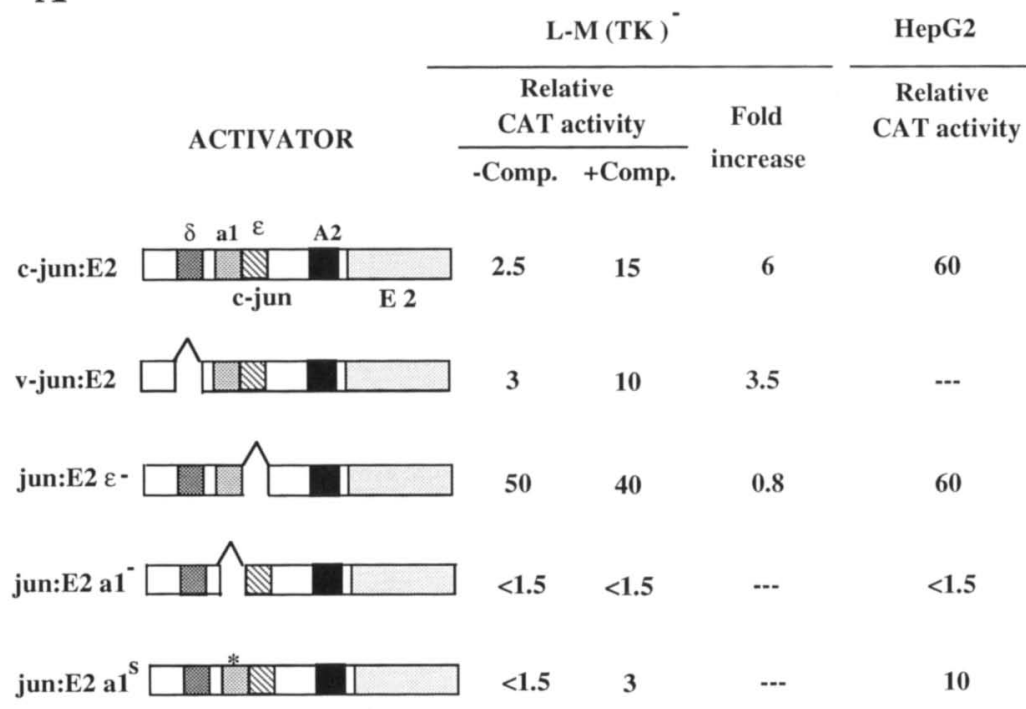

Figure 2. (A) The Al region consists of two functionally distinct domains. The $\mathrm{E} 2$ reporter plasmid $\mathrm{P}_{2}$ CAT was transfected into $\mathrm{L}-\mathrm{M}\left(\mathrm{TK}^{-}\right)$or HepG2 cells with an expression vector encoding the various Jun : E2 hybrids. For the L-M $\left(\mathrm{TK}^{-}\right)$cells, an expression vector encoding c-Jun (+Comp.) or lacking c-Jun (-Comp.) was also included in the transfection. Cells were subsequently processed for CAT assays. The names and schematic structures of the various activator molecules are given in the first column. v-Jun : E2 lacks the $\delta$ region of c-Jun : E2. Amino acids 110-137 are deleted in Jun : E2 $\epsilon^{-}$. Jun : E2 $\mathrm{al}^{-}$hybrids have amino acids 92-103 or 92-107 deleted. Similar results were obtained with either a1- hybrid, and the results for only one deletion are shown. Jun : $\mathrm{E} 2 \mathrm{a} \mathrm{l}^{\mathrm{s}}$ is a substitution mutant that changes amino acids in the al region and is described in Materials and methods. The CAT activities in columns 3,4 , and 6 are relative to that observed in the transfection with the reporter plasmid by itself and fold derepression has the same meaning as in Fig. 1. (-) Not determined. $(B)$ Regulation of c-Jun : E2 in stable cell lines. $\mathrm{L}-\mathrm{M}\left(\mathrm{TK}^{-}\right)$cell lines were constructed that expressed either c-Jun : E2 or Jun : E2 $\epsilon^{-}$, as described in Materials and methods. Two clones of each cell line were cotransfected with $\mathrm{P}_{2} \mathrm{CAT}$ and c-jun or $\mathrm{P}_{2} \mathrm{CAT}$ and a control vector lacking jun sequences. Cells were subsequently processed for CAT assays. The data presented are the average of two clones for each cell line. For each cell line the CAT activity detected in the presence of c-jun $(+$ Comp.) is relative to that observed in its absence (-Comp.).

\section{B}

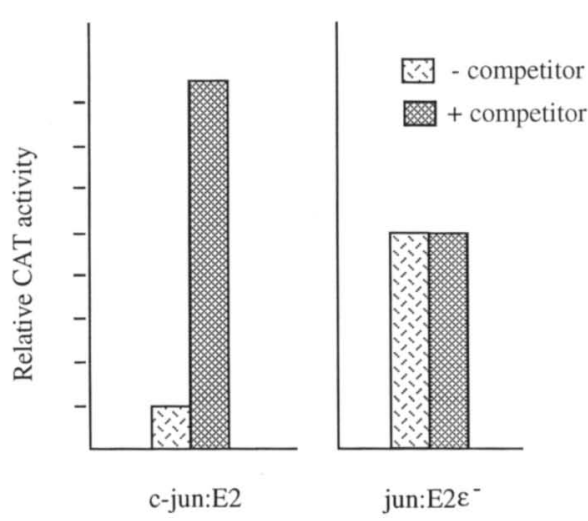

reduced or no trans-activation potential in HepG2, indicating that changes in al compromised the trans-activation function even in a cell line lacking the inhibitor.

To ensure that the altered transcriptional behavior of the Jun : E2 hybrid lacking $\epsilon$ was not dependent on the high amounts of hybrid protein being produced in the cell, as would be expected to occur in a transient transfection, stably transformed cell lines were isolated that expressed c-Jun : E2 and the derivative lacking $\epsilon$. These cell lines expressing Jun : E2 and the derivative were transfected with an $E 2$ reporter plasmid and a vector expressing c-jun or a control vector lacking Jun sequences. Transcriptional activation by c-jun : E2, but not the derivative lacking $\epsilon$, was enhanced by cotransfected c-jun, indicating that the hybrid proteins encoded by the integrated jun : E2 and the $\epsilon^{-} j u n: E 2$ genes were regulated in a manner similar to those produced in a transient transfection (Fig. 2B). These experiments, taken together with the transient assays, establish that the $\mathrm{Al}$ region is a composite of an activation domain (al) and a distinct regulatory subdomain $(\epsilon)$, which is targeted by the cell type-specific Jun inhibitor.
The $\epsilon$ region does not influence stability or nuclear localization of the Iun : E2 hybrid

The identification of the $\epsilon$ region as a site through which the negative regulator of c-Jun operates allowed us to determine whether the interaction of this factor with Jun resulted in altered stability or change in subcellular location. For example, the transcriptional activity of the NF- $\mathrm{KB}$ family of transcription factors is known to be controlled at the level of subcellular location and DNA binding. I $\mathrm{B}$, which is an inhibitor of NF- $\mathrm{kB}$, functions in part by restraining NF- $\mathrm{KB}$ in the cytoplasm, and induction of NF- $\kappa B$ activity occurs by disruption of the NF- $\kappa B:$ I $\kappa B$ complex (for review, see Baeuerle 1991). To address these questions, jun : $E 2$ hybrids that either had the $\epsilon$ region or lacked it were transfected into $\mathrm{L}-\mathrm{M}\left(\mathrm{TK}^{-}\right)$cells and E2 DNA-binding activity recovered in whole-cell extracts and the nuclear fraction was compared for the two proteins by electrophoretic mobility-shift assay (EMSA). Extracts from mock or untransfected cells showed no retarded bands when incubated with an oligomer having an E2-binding site sequence, indicating that the bands 
observed with the jun : E2-transfected cells represented the transfected proteins. Both c-Jun : E2, which is regulated by the inhibitor, and the c-Jun: E2 derivative, which lacks $\epsilon$ and is not regulated, were present in similar amounts in the cell and accumulated in the nucleus to a similar extent (Fig. 3A,B). These results indicate that the inhibitor does not change the stability, nuclear localization, or DNA-binding activity of the Jun : E2 hybrids and suggest that the increased trans-activation property of the $\epsilon^{-}$Jun : E2 hybrid results solely from an increase in the activity of the $\mathrm{Al}$ transcriptional region.

\section{The A1 region consists of two separable functional domains}

We then assesed the effect of the changes in the $\epsilon$ and al regions on the capacity of c-Jun to interact with and

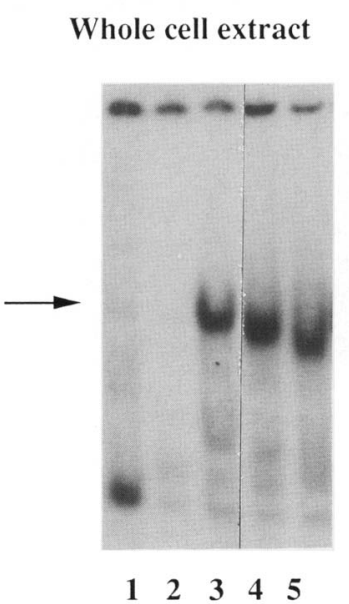

A
Nuclear extract
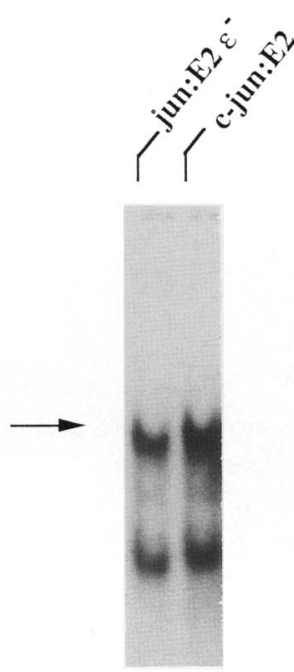

12
Figure 3. The $\epsilon$ region does not influence stability or nuclear localization of the Jun : E2 hybrids. (A) L-M $\left(\mathrm{TK}^{-}\right)$cells were mock transfected (lane 1), the E2 reporter plasmid was transfected by itself (lane 2), with c-jun : E2 (lane 3), with jun : E2 al ${ }^{\mathrm{s}}$ (lane 4), or with jun : E2 $\epsilon^{-}$(lane 5). Whole-cell extracts were prepared from equal numbers of cells and were assayed for E2 DNA-binding activity in an EMSA with an oligonucleotide having the E2-binding sequence. An autoradiograph of the gel is shown; arrow indicates the mobility of the Jun : E2 complex in gels. The faster migrating complexes reflect nonspecific binding of other proteins in the extract, and the signals are competed with excess calf thymus DNA. $(B) \mathrm{L}-\mathrm{M}\left(\mathrm{TK}^{-}\right)$cells were transfected with $\mathrm{P}_{2} \mathrm{CAT}$ and either jun : E2 $\epsilon^{-}$(lane 1) or c-jun : E2 (lane 2). Cells were microfractionated into cytoslic and nuclear fractions, and the nuclear extracts from equal number of cells were assayed for E2 DNA-binding activity as in $A$. The arrow indicates the mobility of the Jun : E2 complex in gels. The faster migrating complex probably represents a proteolytic product generated during fractionation. The portion of the gel, where the free probe migrates, has been cut off in both $A$ and $B$.
COMPETITOR

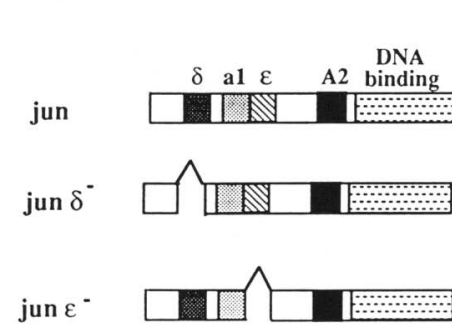

jun â

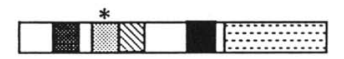

jun $\varepsilon$

GGGSGGGTGG

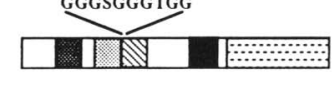

$\operatorname{jun} \varepsilon^{p}$

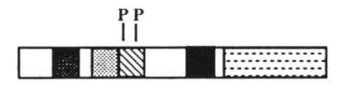

jun $\varepsilon s$

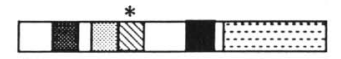

jun B

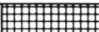

Fold enhancement

of a GAL4:jun

hybrid

23

15

3.5

21

$<2$

$<2$

21

3
Figure 4. The $\epsilon$ region is necessary for superenhancement of a GAL4: Jun hybrid by c-Jun. $\mathrm{G}_{5}$ BCAT was transfected into cells with a plasmid encoding a gal4 : jun hybrid (gal4 : jun 5-253) and a CMV expression vector encoding the various Jun proteins listed as competitors. Cells were subsequently processed for CAT assays. The $\epsilon^{-}$and $a l^{\mathrm{s}}$ mutations are as described in the legend to Fig. 2. jun $\epsilon^{\mathrm{i}}$ has an insertion of 10 amino acids between the al and $\epsilon$ domains, $j u n \epsilon^{\mathrm{P}}$ changes glycine to proline in the $\epsilon$ region, and iun $\epsilon^{\mathrm{s}}$ has 5 amino acid changes in the carboxyterminal part of $\epsilon$, making the sequence more similar to junB. The fold enhancement in CAT activity observed when the various competitors were transfected is given in the second column. In this experiment trans-activation of $\mathrm{G}_{5} \mathrm{BCAT}$ by the GAL4 : Jun hybrids resulted in a 10-fold increase in CAT activity. The data for $j u n B$ was obtained in a separate experiment.

compete with the inhibitor. The capacity of the jun mutants to compete with the inhibitor was evaluated by determining the extent to which these proteins superenhanced activation by a gal4: jun hybrid (Fig. 4). The iun derivative lacking $\epsilon$ failed to superenhance the gal4 : jun hybrid indicating that it competed poorly for the inhibitor. Removal of the al region also resulted in a Jun protein that was no longer superenhanced. In contrast, a mutant with a substitution in the al domain superenhanced the gal4: jun hybrid to the same extent as the parental c-Jun protein. This mutation significantly compromises the transcriptional activation function of the Al region (see Fig. 2) but does not appear to affect the interaction of the inhibitor with c-Jun. Taken together, these results therefore suggest that the $\epsilon$ sequences govern the interaction of the inhibitor with Jun and that the amino acid residues in the al domain are not directly involved in the interaction of the inhibitor but that removal of the al sequences probably alters the structure 
of the protein so that it no longer interacts with the inhibitor. These findings along with the findings presented in Figure 2 indicate that the transcriptional activation function in $A 1$ is separable from the site through which it is regulated.

$j u n B$, a homolog of c-jun, differs biochemically and biologically from c-jun. We therefore evaluated its capacity to superenhance the gal4 : jun hybrid and found that it failed to superenhance the hybrid. The two proteins have related but divergent sequences in the part of the molecule corresponding to the al and $\epsilon$ regions of $c$-Jun. The $\epsilon$ region of $c$-Jun differs from the corresponding region of JunB in two major respects. The carboxyl terminus of $\epsilon$ shows nonconservative changes, and there is an insertion of 10 amino acids in JunB corresponding to the boundary of al and e. To determine whether either of these changes would affect the $\epsilon$ region in c-Jun, we made a mutant that had 10 amino acids inserted between the al and $\epsilon$ of $c$-Jun (Jun $\epsilon^{i}$ ), and one that changed 5 amino acids in the carboxy-terminal portion of $\epsilon$ (Jun $\epsilon^{\mathbf{s}}$ ) to make it more similar to the JunB sequence. The $\epsilon$ substitution mutant superenhanced the gal4: jun hybrid, whereas the insertion mutant failed to superenhance. Also, a mutant in which prolines were substituted for two glycines in the amino terminus of $\epsilon$ (Jun $\left.\epsilon^{\mathrm{p}}\right)^{\mathrm{p}}$ failed to superenhance. Thus, although the contribution of individual amino acids in $\epsilon$ toward the interaction with the inhibitor are not established, the integrity of the overall structure of this region of the protein appears to be important for efficient interaction with the inhibitor.

\section{The VP16 activation domain can be regulated by the Jun inhibitor and $\epsilon$}

To provide more decisive evidence that the $\mathrm{Al}$ region of Jun consists of functionally distinct domains al and $\epsilon$ and that sequences within al are probably not directly involved in interactions with the inhibitor, we determined whether a different activation domain from another transcription factor could be regulated by the $\epsilon$ region and the Jun inhibitor. To test this possibility, the al domain was replaced by the activation domain from the herpes simplex virus type-1 protein VP16 (Cress and Triezenberg 1991). This activation domain, which has a preponderance of acidic amino acids, shows no sequence similarity to the al domain and confers transcriptional activity on a number of DNA-binding domains in different cell types.

Two c-Jun : E2 hybrids in which the al domain had been removed to varying extents were used as recipients to insert the minimal VP16 activation domain (amino acid sequence LASPEGEDVA MAHADALDDF DLDMLGDGDI QT). Both hybrids trans-activated the reporter plasmid in $\mathrm{L}-\mathrm{M}\left(\mathrm{TK}^{-}\right)$cells, but the trans-activation was significantly lower than that observed with a chimera in which the VP16 activation domain was fused directly to the E2 DNA-binding domain (Fig. 5; V.R. Baichwal et al., unpubl.). This result indicated that the trans-activation potential of the VP16 activation domain was attenuated, when evaluated in the context of the Jun sequences. To demonstrate that this lowered activity of the VP16 Jun : E2 hybrids was a consequence of repression of the activation domain by the c-Jun inhibitor, c-jun was transfected along with the hybrid as a competitor. Transfection of c-iun resulted in enhancement of trans-activation by the hybrid, indicating that the VP16 Jun : E2 was repressed by the inhibitor. This conclusion was further substantiated by demonstrating that in the absence of a competitor, a VP16 Jun : E2 hybrid that lacked the $\epsilon$ region was more active than the hybrid having $\epsilon$ and, furthermore, was not superenhanced by iun. As expected, VP16 Jun : E2 hybrids either having $\epsilon$ or lacking it accumulated to the same extent in the nuclear fraction of $\mathrm{L}-\mathrm{M}\left(\mathrm{TK}^{-}\right)$cells, and the difference in transcriptional activity of the two hybrids was not observed in HepG2 cells that lack Jun inhibitory activity (V.R. Baichwal et al., unpubl.).

To further establish that a Jun molecule having the VP16 activation domain in place of the al domain can interact efficiently with the inhibitor, we showed that such a VP16: Jun chimera superenhanced activation by the GAL4: Jun hybrid and thus acted as an effective competitor for the Jun inhibitor. These results indicate that the VP16 activation domain is appropriately regulated by the Jun inhibitor by interaction with the $\epsilon$ region; therefore, even unrelated heterologous activators can be negatively controlled by the $\delta / \epsilon$ arrangement.

\section{Discussion}

It is now well established that sequence-specific DNAbinding transcription factors typically consist of a domain responsible for recognition of DNA and a separable domain that is involved in carrying out the activation function of the protein (Johnson and McKnight 1989; Mitchell and Tiian 1989). In vitro transcription assays and transfection studies have helped to identify and characterize activation domains in transcription factors and classify them into groups based on relatedness of amino acid sequence. It has not yet been established, however, how activation domains function, and not much is known about how their activity is regulated. The difficulty in studying their regulation stems in part from the complex nature of the transcription reaction involving multiple factors and the inability to reconstitute in vitro a transcription reaction made entirely with purified and characterized components.

We have used a transfection assay to study the regulation of c-Jun transcriptional activity. Previously, we found that the Al region of Jun was a target for regulation by a cell-specific factor (Baichwal and Tjian 1990). In cell lines lacking this regulator, the $\mathrm{A} 1$ region functions as a transcriptional activation domain, suggesting that the regulator functions by controlling the activity of this domain. Other possible mechanisms for regulation by this factor, however, could not be excluded. The findings presented here demonstrate that the Al region harbors a bipartite activation domain, which consists of two distinct and functionally separable domains. One domain is 
A

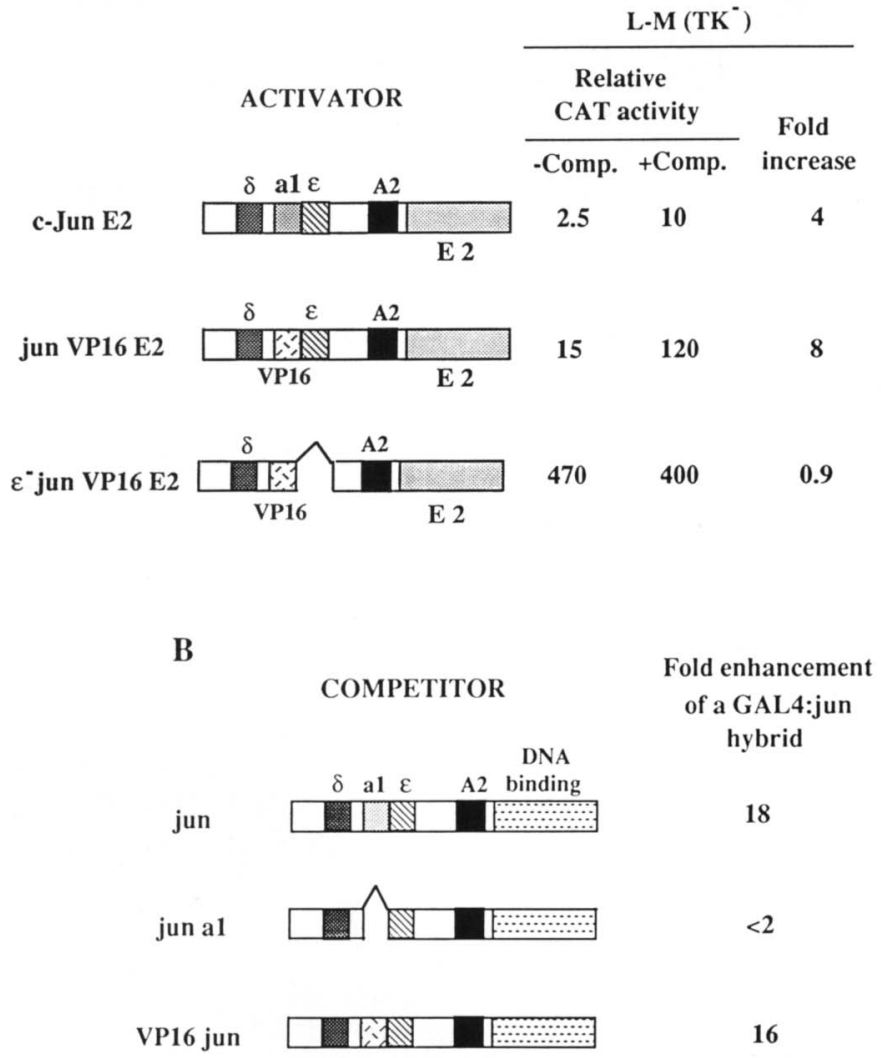

Figure 5. The VP16 activation domain can be regulated by the Jun inhibitor and $\epsilon .\langle A| \mathrm{P}_{2} \mathrm{CAT}$ was transfected into $\mathrm{L}-\mathrm{M}\left(\mathrm{TK}^{-}\right)$or HepG2 cells with an expression vector encoding the various jun : E2 hybrids. For the $\mathrm{L}-\mathrm{M}\left(\mathrm{TK}^{-}\right)$cells an expression vector encoding c-jun (+ Comp.) or lacking c-iun (-Comp.) was also included in the transfection. Cells were subsequently processed for CAT assays. The schematic structures of the various activator molecules are given in the first column. Jun VP16 E2 has the VP16 activation domain in place of the al domain, and $\epsilon^{-}$Jun VP16 E2 is a derivative of Jun VP16 E2 that lacks the $\epsilon$ region. The CAT activities in second and third columns are relative to that observed in the transfection with the reporter plasmid by itself, and fold derepression has the same meaning as in Fig. 1. Similar results were obtained with Jun VP16 E2 hybrids constructed from either of the al ${ }^{-}$hybrids lacking amino acids $92-103$ or $92-107$, and the results for only one VP16 Jun : E2 hybrid are shown. (B) $\mathrm{G}_{5}$ BCAT was transfected into cells with a plasmid encoding a gal4:jun hybrid (gal4: jun 5-253) and a CMV expression vector encoding the various Jun proteins listed as competitors. Cells were subsequently processed for CAT assays. The fold enhancement observed in CAT activity when the various competitors were transfected is given in the second column. In these experiments trans-activation of $\mathrm{G}_{5} \mathrm{BCAT}$ by the GAL4 : Jun hybrids resulted in a sixfold increase in CAT activity. a bona fide potent transcriptional activation domain (a1), which may be as small as $\sim 20$ amino acids; and a second adjacent region $(\epsilon)$, which is 27 amino acids long, is a site through which the c-Jun regulator operates to control al. The interaction of the regulator with $\epsilon$ leads to repression of the al domain; thus, the genetically defined regulator of Jun functions by inhibiting the al domain (Fig. 6). Efficient interaction of the inhibitor with Jun appears to be critically dependent on the structure of the al and $\epsilon$ regions, as evidenced by the failure of mutants in these regions and of JunB to act as effective competitors. This model for the modular organization of the $\mathrm{Al}$ region is confirmed by the finding that the acidic activation domain of VP16 is regulated by the Jun inhibitor as is the a 1 region, when it is juxtaposed next to the $\epsilon$ region.

The cell-specific regulation of c-Jun was initially revealed in studies examining the role of the $\delta$ region in the regulation of c-Jun activity. This 27 -amino-acid region, which is deleted in the retroviral oncogene product $\mathrm{v}$-Jun, inhibits transcriptional activity of c-Jun both in vitro and in vivo and also restrains its transforming potential (Bohmann and Tjian 1989; Bos et al. 1990). Although the $\delta$ region was involved in regulating the interaction of the inhibitor with Jun, it was not the target site through which the inhibitor operated to control Jun activity, as a v-jun : E2 hybrid was still partially repressed by the inhibitor (Baichwal and Tiian 1990). These perplexing results are now explained by the identification of the $\epsilon$ region as another negative regulatory region in
c-Jun. In contrast to $\delta$, removal of $\epsilon$ from Jun : E2 hybrids results in complete relief of repression. Thus, the inhibitor operates through $\epsilon$, and not $\delta$, to repress the al domain. The presence of the $\delta$ region probably enhances the interaction of the inhibitor with $\epsilon$. The extent of this subtle but important effect of the $\delta$ region would clearly depend on the amount of inhibitor and the Jun protein in cells. The functioning of the $\delta$ region ensures that the al region would be repressed even in cells with low amounts of the inhibitor, and that repression can occur even in the absence of a functional $\delta$ region in cells with high levels of the inhibitor.

It is interesting that analysis of tumor induction in v-jun transgenic mice revealed that the transgenic animals were initially normal but showed abnormal hyperplastic growth, which progressed in some instances to dermal fibrosarcomas on wounding (Schuh et al. 1990). This multistep growth transition was associated with an increase in v-jun expression and was also related to the number of copies of the transgene in the animals, leading the investigators to conclude that there was a quantitative requirement or threshold for $\mathrm{v}$-Jun action. The finding that the $\epsilon$ region is the primary site of regulation by the inhibitor and the fact that this region is present in $\mathrm{v}$-Jun could help to explain why v-Jun, although derepressed, is not acutely oncogenic in mice.

The involvement of the $\delta$ region, a biologically critical part of the molecule in regulation by the inhibitor, suggests that regulation by this factor is physiologically im- 

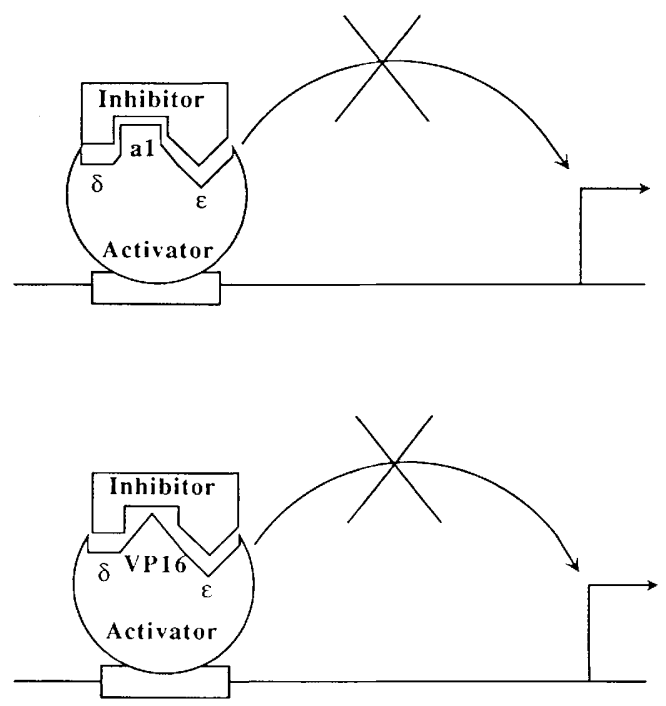

Figure 6. A schematic model for the regulation of an activation domain by the $\epsilon$ and $\delta$ regions of $c$-Jun and the c-Jun inhibitor. (Top) Regulation of the al activation domain by the c-Jun inhibitor. The transcriptional activator is shown binding to a site upstream of the promoter. The al activation domain, however, cannot transmit a signal to the general transcription machinery to enhance utilization of the promoter, because the Jun inhibitor, which interacts with $\epsilon$ and $\delta$, probably masks al and blocks its action. (Bottom) A heterologous activation domain, such as the one from VP16, is also repressed by the inhibitor, when the activation domain is placed between the $\epsilon$ and $\delta$ regions of c-Jun. The inhibitor, therefore, probably does not contact the activation domain sequences, but its interactions with the $\epsilon$ and $\delta$ region is sufficient to block the function of the activation domain.

portant. Also the demonstration that the Al region of Jun is a target for regulation by signal transduction pathways involving $\operatorname{src}$ or ras reinforces the importance of the inhibitor in physiological processes involving Jun (Baichwal and Tjian 1990). The relationship between transcriptional activation and transformation by iun is not clear, however, as a recent study in CEFs suggests an inverse correlation between the two (Havarstein et al. 1992); whereas other studies have shown a direct correlation between trans-activation and transformation in rodent cells (Alani et al. 1991; Lloyd et al. 1991). Determining the effect of deleting the $\epsilon$ region on the transforming activity of Jun would evaluate directly the contribution of the inhibitor and the $\epsilon$ region to the biolog. ical activity of jun and may help to clarify the relationship of transcriptional activation to transformation for jun.

The role of phosphorylation-dephosphorylation in regulation by the c-Jun inhibitor is unclear (Alvarez et al. 1991; Black et al. 1991; Pulverer et al. 1991; Smeal et al. 1991). c-Jun is phosphorylated in vitro by MAP kinases at Ser-62 and Ser-72, and phosphorylation at these sites is enhanced in vivo by exposing cells to TPA or transfection of the ras oncogene. Changing the serines to nonphosphorylatable amino acids leads variably either to loss of trans-activation or decreased enhancement of trans-activation by cotransfected ras. A model has been proposed on the basis of these observations wherein the phosphorylation of the c-Jun activation domain converts it into a more potent trans-activator in a manner analogous of the regulation of CREB by protein kinase A (Pulverer et al. 1991; Smeal et al. 1991). In this scenario the c-Jun inhibitor would merely be preventing these phosphorylation events or reversing them. Intriguingly, however, neither site of phosphorylation maps to an activation domain in Jun, and deletion of that region of the protein has no effect on trans-activation by Jun (Angel et al. 1989; Baichwal and Tjian 1990) or enhancement in trans-activation of a Jun chimera that is induced by transfection of ras (Baichwal et al. 1991). Furthermore, the finding that the constitutively active acidic activation domain of VP16 is regulated like the al domain when substituted for it establishes that the inhibitor can repress a constitutive activation domain and does not function only by preventing phosphorylation.

One way in which a protein kinase may modulate c-Jun transcriptional activity is by phosphorylation of threonine residues in the al domain. The al domain mapped in these studies has both serines and threonines, and the al substitution mutant that has alanines in place of threonines is impaired in its trans-activation function. It is noteworthy that the threonines in al occur in the sequence TTTPTPT and that threonines in such a sequence context are known to be phosphorylated by proline-dependent protein kinases, which include CDC2 and MAP kinases (for review, see Hill and Vulliet 1991). Therefore, it remains possible that phosphorylation of the al domain by a CDC2 or MAP kinase may potentiate trans-activation by this domain. The finding that the constitutively active acidic activation domain of VP16 is regulated like the al domain when placed in the context of $\epsilon$, however, establishes firmly that the inhibitor can repress a constitutive activation domain irrespective of any phosphorylation event and is not likely to function simply by preventing phosphorylation.

Further insight into the regulation of Jun by the inhibitor and analysis of its role in regulating cell growth and proliferation would be facilitated by identification of the inhibitory activity and having other assays to detect it. The characterization of the Al region as a bipartite activation domain should aid in the biochemical identification of the inhibitor. The inhibitor Jun complex is probably not a stable one, as no proteins specifically associated with the $\epsilon$ region are coprecipitated with Jun or Jun chimeras or detected as additional bands in gel-shift assays (Fig. 3; V.R. Baichwal et al., unpubl.). A GAL4 : Jun hybrid without an $\epsilon$ region, however, is a stronger transcriptional activator than one having it in an in vitro transcription assay, suggesting the presence of an $\epsilon$-dependent inhibitory activity in extracts (A.Vasserot and R.Tjian, unpubl.).

\section{Materials and methods}

\section{Cell culture and transfections}

$\mathrm{L}-\mathrm{M}\left(\mathrm{TK}^{-}\right)$and HepG2 cells were transfected as described previously (Baichwal and Tjian 1990; Baichwal et al. 1991). The 
procedures for CAT assays have been described (Courey and Tjian 1988). All transfections were done in duplicate and usually repeated three to five times; the data presented are the average of two experiments (four transfections). Stable clones of $\mathrm{L}-\mathrm{M}\left(\mathrm{TK}^{-}\right)$expressing $\mathrm{c}-\mathrm{Jun}: \mathrm{E} 2$ or Jun : E2 $\epsilon^{-}$were constructed by cotransfecting the plasmid encoding the chimeric proteins with $\mathrm{pSV}_{2} \mathrm{Neo}$ and $\mathrm{pH} 100$. Drug-resistant cell clones were selected with G418 $(750 \mu \mathrm{g} / \mathrm{ml})$.

\section{Plasmids}

The CAT reporter plasmids $\mathrm{G}_{5}$ BCAT (Lillie and Green 1989) and $\mathrm{P}_{2}$ CAT (Choe et al. 1989), which have binding sites for the transcriptional activators GAL4 and E2, respectively, have been described. pH100 was a gift from Lue Yan and M. Botchan /University of California, Berkeley) and contains the upstream regulatory region of $\mathrm{BPV}$ in pUCl18. The chimeric Jun proteins GAL4 : Jun 5-253, GAL4 : Jun 139-253, and GAL4 : Jun 5-154 and the E2 hybrids c-Jun : E2 and v-Jun : E2 have been described (Baichwal and Tjian 1990; Baichwal et al. 1991). The numbering system used for the GAL4 : Jun hybrids and Jun proteins is as described in Baichwal and Tjian (1990). In this system the first methionine in c-Jun is numbered 10; the full-length c-Jun protein begins at 5 . The gal4: iun hybrids 5-150, 5-137, 5-110, 5-110*, and 5-77 were made by exonuclease III digestion of gal4 : iun 5-253 cut with EagI and KpnI. The plasmid ends were then rendered blunt with Klenow and self-ligated. The nomenclature of the gal4 : jun hybrids takes the form gal4 : jun Y-Z, where $\mathrm{Y}-\mathrm{Z}$ indicates the region of c-jun present in the hybrid. The extra amino acids introduced by the linker sequences before the stop codon are different for each hybrid and are as follows: gal4 : jun 5-150 has the sequence FVL; gal4 : jun 5-137 has VPPSLD; gal4: jun 5-110 has DPSTVPRGIRALDK; and gal4 : jun 5-110* has DPSTVPPSLD. The $\epsilon^{-}, \mathrm{a} 1^{-}, \mathrm{a} 1^{\mathrm{s}}, \epsilon^{\mathrm{i}}, \epsilon^{\mathrm{p}}$, and $\epsilon^{\mathrm{s}}$ derivatives were constructed by site-specific mutagenesis by use of the method of Kunkel (1985). The mutagenesis was done on a c-jun template, and after confirming the mutation by dideoxy sequencing, a DNA fragment having the changed sequences was substituted for the normal sequences in a cytomegalovirus (CMV) c-jun DNA- (Baichwal and Tjian 1990) background and c-jun : E2. For construction of the c-jun DNAderivatives, a BamHI-PstI fragment of c-jun DNA ${ }^{-}$was substituted by a similar fragment having the mutated sequences. The c-jun : E2 derivatives were constructed by replacing an EagI fragment of c-jun : E2 having the CMV and jun sequences with the corresponding fragment from the iun $\mathrm{DNA}^{-}$derivatives having the site-specific mutation. The oligonucleotide sequences used for the mutagenesis to construct the $\epsilon^{-}$, the two $\mathrm{al}^{-}, \mathrm{al}^{\mathrm{s}}, \epsilon^{\mathrm{i}}, \epsilon^{\mathrm{p}}$, and $\epsilon^{\mathrm{s}}$ changes are, respectively, CCGACGTGAC GCTGGGGCAC AGGAAC $\left(\epsilon^{-}\right)$; CTGGAACTGG GTCTGGATAT CTAGGCGCTC $\mathrm{C}\left(\mathrm{al}^{-}\right)^{-}$; TCTTGGGGCA CTGGATATCT AGGCGCTCC $\mid \mathrm{a}^{-}{ }^{-}$; GCACAGGAAC TGGGCGGGGG CCGGCGCGGC GGCGATGTGC CCGTTGCT $\left(\mathrm{al}^{\mathrm{s}}\right)_{\text {; }}$ ATCTGTCACG TTTCCTCCTG TACCTCCACC GCTTCCACCT CCCTTGGGGC ACAG $\left(\epsilon^{\mathrm{i}}\right)$; GGCGCGCACG AAGGGCTCGG CGAAGGGCTC CTGCTCATC $\left(\epsilon^{\mathrm{p}}\right)$; and CGACGTGACG CTGTTCAGCT GGCTCTGTTT GTGCAGTTCG TCCAGGGCGC GCAC $\left(\epsilon^{s}\right)$. The amino acid changes introduced by these mutations are deletions of amino acids $110-137\left\langle\epsilon^{-}\right|, 92-103$ $\left(\mathrm{al}^{-}\right)$, and $92-107\left(\mathrm{al}^{-}\right)$; conversions of $\mathrm{I} 89$ to $\mathrm{D}$, of $\mathrm{T} 98,99,100$, 102 , and 104 to $\mathrm{A}\left(\mathrm{al}^{\mathrm{s}}\right)_{\text {; }}$ insertion of GGGSGGGTGG between amino acids 110 and $111\left(\epsilon^{\mathrm{i}}\right)$; conversion of $\mathrm{G} 118$ and 122 to $\mathrm{P}\left(\epsilon^{\mathrm{P}}\right)$; and conversion of $A 128$ to $D, S 132$ to $K, N 134$ to $S, T 135$ to $Q$, and $P 137$ to $N\left\langle\epsilon^{\mathrm{s}}\right\rangle$.

The two al ${ }^{-}$derivatives behaved similarly in all assays, and the data for only one of them are given. Substitution of the al domain by the VP16 activation domain was done by synthesiz- ing a double-stranded oligonucleotide, which has the VP16 activation domain sequences (Cress and Triezenberg 1991) (CCGAGGGCGA GGACGTGGCC ATGGCCCACG CCGACGCCCT GGACTTCGAC CTGGACATGC TGGGCGACGG CGATATCGGC CGGTAC), and inserting it in both $\mathrm{al}^{-}$derivatives. The sequence of the VP16 Jun : E2 hybrids starting from amino acid 80 in Jun and ending at amino acid 104 or 108 reads LASPEGEDVA MAHADALDDF DLDMLGDGDI QT or LASPEGEDVA MAHADALDDF DLDMLGDGDI QC. The VP16 sequences were introduced into a c-jun background by providing $A v a I$ and EcoRV sites on the oligonucleotides to insert it into the AvaI and EcoRV sites of the a1 ${ }^{-}$derivatives. As with the other site-specific mutants, a BamHI-Pst jun fragment having the VP16 activation domain from this hybrid was then substituted into CMV jun DNA ${ }^{-}$. The VP16 jun : E2 hybrid was then constructed by replacing an EagI fragment of c-jun : E2 with the corresponding fragment from the VP16 jun DNA- derivative, which had the CMV, VP16, and jun sequences. Both VP16 iun : E2 hybrids behaved similarly, and data for only one is shown. The $\epsilon^{-}$VPl6 jun : E2 derivative was constructed from the VP16 jun : E2 hybrid by deleting the NaeI-EcoRV fragment in jun that removes the $\epsilon$ sequences and additional intervening sequences between the $\epsilon$ and A2 domains.

\section{DNA-binding activity of Jun : E2 hybrids}

Six micrograms of $\mathrm{P}_{2} \mathrm{CAT}$ was transfected with 9 micrograms of the various iun : E2 hybrids into $\mathrm{L}-\mathrm{M}\left(\mathrm{TK}^{-}\right)$cells. Two days after transfection, cells were washed with PBS and harvested by scraping. For detection of total DNA-binding activity in extracts, cell pellets were lysed by resuspension in buffer A [20 mM HEPES (pH 7.6), 20\% glycerol, $420 \mathrm{~mm}$ potassium chloride, $2 \mathrm{mM}$ magnesium chloride, $1 \mathrm{~mm}$ phenylmethylsulfonyl fluoride, $1 \%$ Trasylol] and sonication, and equal amounts of extracts were used for EMSAs. For preparation of nuclear extracts on a microscale, cells were resuspended in $10 \mathrm{~mm}$ HEPES ( $\mathrm{pH} 7.6$ ), $1.5 \mathrm{~mm}$ magnesium chloride, and $10 \mathrm{~mm}$ potassium chloride and lysed by the addition of $0.05 \%$ NP- 40 . Nuclei were collected by centrifugation in a microcentrifuge for $5 \mathrm{~min}$ and extracted with buffer A by sonication. Nuclear debris was removed by centrifugation, and equal amounts of nuclear extracts were used for the determination of DNA-binding activity. For the gel shifts an end-labeled oligonucleotide having the E2-binding site GGTCAAACCGTCTTCGGTGCTCGAAAA was incubated at $30^{\circ} \mathrm{C}$ for 20 min with extracts containing $10 \mathrm{mM}$ HEPES (pH 7.4), 2 $\mathrm{mM}$ magnesium chloride, $5 \%$ glycerol, a final salt concentration of $200 \mathrm{~mm}$ potassium chloride, and $20 \mathrm{mg} / \mathrm{ml}$ of sonicated calf thymus DNA as nonspecific competitor. Complexes were resolved on a $4.5 \%$ acrylamide gel $130 \%$ acrylamide and $0.8 \%$ bisacrylamide) in $0.5 \times \mathrm{TBE}$ at room temperature. Complexes were typically detected in overnight exposures at $-80^{\circ} \mathrm{C}$.

\section{Acknowledgments}

We thank L. Attardi, B. Dynlacht, G. Peterson, and A. Vasserot for their comments on the manuscript. V.R.B. is a Special Fellow of the Leukemia Society of America. This work was partly funded by a grant from the National Institutes of Health to R.T.

The publication costs of this article were defrayed in part by payment of page charges. This article must therefore be hereby marked "advertisement" in accordance with 18 USC section 1734 solely to indicate this fact.

\section{References}

Abate, C., L. Patel, F.J. Rauscher III, and T. Curran. 1990. Redox regulation of Fos and Jun DNA binding activity in vitro. Science 249: 1157-1161. 
Alani, R., P. Brown, B. Binetruy, H. Dosaka, R.K. Rosenberg, P. Angel, M. Karin, and M.J. Birrer. 1991. The transactivating domain of the c-jun proto-oncoprotein is required for cotransformation of rat embryo cells. Mol. Cell. Biol. 11: 6286-6295.

Alvarez, E., I.C. Northwood, F.A. Gonzalez, D.A. Latour, A. Seth, C. Abate, T. Curran, and R.J. Davis. 1991. Pro-Leu-Ser/ Thr-Pro is a consensus primary sequence for substrate protein phosphorylation. J. Biol. Chem. 266: 152770-15285.

Angel, P. and M. Karin. 1991. The role of jun, fos and AP-1 complex in cell proliferation and transformation. Biochim. Biophys. Acta 1072: 129-157.

Angel, P., T. Smeal, J. Meek, and M. Karin. 1989. jun and v-jun contain multiple regions that participate in transcriptional activation in an interdependent manner. New Biol. 1: 35-43.

Auwerx, J. and P. Sassone-Corsi. 1991. IP-1: A dominant inhibitor of Fos/Jun whose activity is modulated by phosphorylation. Cell 64: 983-993.

Baeuerle, P.A. 1991. The inducible transcription activator NF$\kappa \mathrm{B}$ : Regulation by distinct subunits. Biochim. Biophys. Acta 1072: 63-80.

Baichwal, V.R. and R. Tjian. 1990. Control of c-Jun activity by interaction of a cell-specific inhibitor with regulatory domain $\delta$ : Differences between v- and c-jun. Cell 63: 815-825.

Baichwal, V.R., A. Park, and R. Tjian. 1991. v-src and EJ ras alleviate repression of c-Jun by a cell-specific inhibitor. $\mathrm{Na}$ ture 352: 165-168.

Black, E.J., A.J. Street, and D.A.F. Gillespie. 1991. Protein phosphatasae $2 \mathrm{~A}$ reverses phosphorylation of c-jun specified by the delta domain in vitro: Correlation with oncogenic activation and deregulated transactivation activity of $\mathrm{v}$-jun. Oncogene 6: 1949-1958.

Bohmann, D. and R. Tjian. 1989. Biochemical analysis of transcriptional activation by jun: Differential activity of c-and v-jun. Cell 59: 709-717.

Bos, T.J., F.S. Monteclaro, F. Mitsunobu, A.R. Ball, C.H.W. Chang, T. Nishimura, and P.K. Vogt. 1990. Efficient transformation of chicken embryo fibroblasts by c-Jun requires structural modification in coding and noncoding sequences. Genes \& Dev. 4: 1677-1687.

Boyle, W.J., T. Smeal, L.H.K. Defize, P. Angel, J.R. Woodgett, M. Karin, and T. Hunter. 1991. Activation of protein kinase C decreases phosphorylation of $\mathrm{c}$-Jun at sites that negatively regulates its DNA binding activity. Cell 64: 573-584.

Choe, J., P. Vaillancourt, A. Stenlund, and M. Botchan. 1989. Bovine papillomavinus type 1 encodes two forms of a transcriptional repressor: Structural and functional analysis of new viral cDNAs. J. Virol. 63: 1743-1755.

Courey, A.J. and R. Tjian. 1988. Analysis of $\mathrm{Spl}$ in vivo reveals multiple transcriptional domains, including a novel glutamine-rich activation motif. Cell 55: 887-898.

Cress, W.D. and S.J. Triezenberg. 1991. Critical structural elements of the VP16 transcriptional activation domain. Science 251: 87-90.

Curran, T. and B.R. Franza Jr. 1988. Fos and jun: The AP-1 connection. Cell 55: 395-397.

Gonzalez, G.A. and M.R. Montminy. 1989. Cyclic AMP stimulates somatostatin gene transcription by phosphorylation of CREB at serine 133. Cell 59: 675-680.

Hill, L. and P.R. Vulliet. 1991. Proline-directed protein phosphorylation and cell cycle regulation. Curr. Opin. Cell Biol. 3: $176-184$.

Havarstein, L.S., I.M. Morgan, W.-Y. Wong, and P.K. Vogt. 1992. Mutations in the jun delta region suggest an inverse correlation between transformation and transcriptional activation. Proc. Natl. Acad. Sci. 89: 618-622.
Johnson, P.F. and S.L. McKnight. 1989. Eukaryotic transcriptional regulatory proteins. Annu. Rev. Biochem. 58: 799839.

Kunkel, T.A. 1985. Rapid and efficient site-specific mutagenesis without phenotypic selection. Proc. Natl. Acad. Sci. 82: 488-492.

Lamb, P. and S.L. McKnight. 1991. Diversity and specificity in transcriptional regulation: The benefits of heterotypic dimerization. Trends Biochem. Sci. 16: 417-422.

Lee, C.Q., Y. Yun, J.P. Hoeffler, and J.F. Habener. 1990. CyclicAMP-responsive transcriptional activation of CREB327 involves interdependent phosphorylation subdomains. $E M B O$ I. 9: 4455-4465.

Lewin, B. 1991. Oncogenic conversion by regulatory changes in transcription factors. Cell 64: 303-312.

Lillie, J.W. and M.R. Green. 1989. Transcription activation by the adenovirus Ela protein. Nature 338: 39-44.

Lloyd, A., N. Yancheva, and B. Wasylyk. 1991). Transformation suppressor activity of a jun transcription factor lacking its activation domain. Nature 352: 635-638.

Mitchell, P.J. and R. Tjian. 1989. Transcriptional regulation in mammalian cells by sequence-specific DNA binding proteins. Science 245: 371-378.

Pulverer, B.J., J.M. Kyriakis, J. Avruch, E. Nikolakaki, and J.R. Woodgett. 1991. Phosphorylation of c-jun mediated by MAP kinases. Nature 353: 670-674.

Schuh, A.C., S.J. Keating, F.S. Monteclaro, P.K. Vogt, and M.L. Breitman. 1990. Obligatory wounding requirement for tumorigenesis in v-jun transgenic mice. Nature 346: 756-759.

Smeal, T., B. Binetruy, D.A. Mercola, M. Birrer, and M. Karin. 1991. Oncogenic and transcriptional cooperation with $\mathrm{Ha}-$ ras requires phosphorylation of c-Jun on serines 63 and 73 . Nature 354: 494-496.

Vogt, P.K. and I. Morgan. 1990. The genetics of jun. Sem. Cancer Biol. 1: 27-36. 


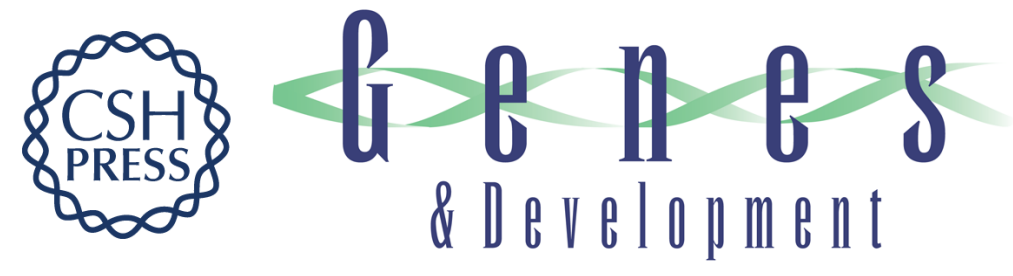

\section{The cell-type-specific activator region of c-Jun juxtaposes constitutive and negatively regulated domains.}

V R Baichwal, A Park and R Tjian

Genes Dev. 1992, 6:

Access the most recent version at doi:10.1101/gad.6.8.1493

References This article cites 31 articles, 8 of which can be accessed free at:

http://genesdev.cshlp.org/content/6/8/1493.full.html\#ref-list-1

License

Email Alerting

Service

Receive free email alerts when new articles cite this article - sign up in the box at the top right corner of the article or click here.

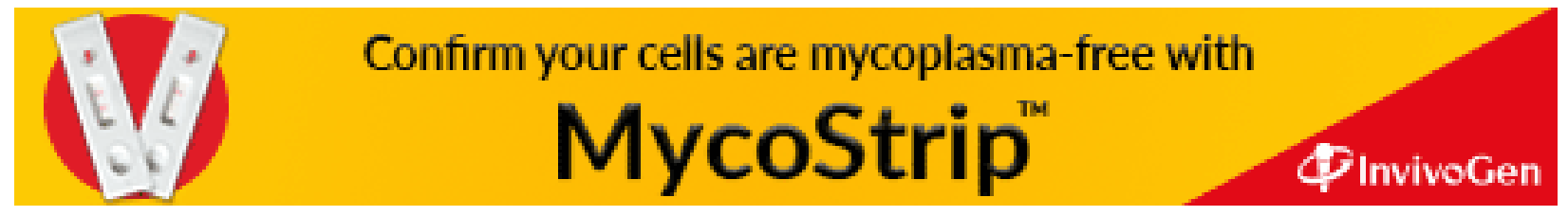

